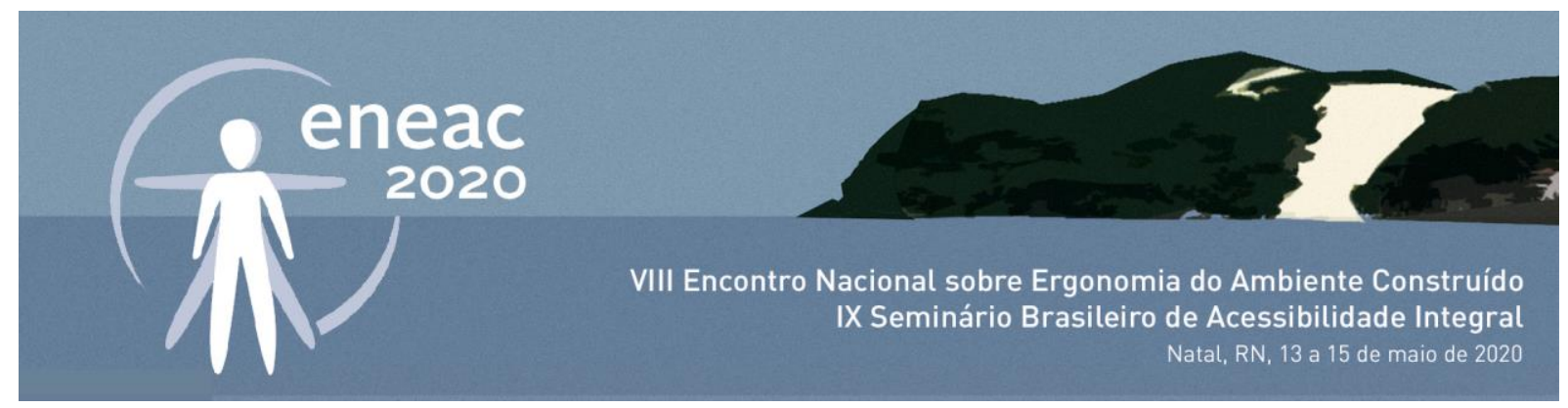

\title{
O ambiente escolar e a importância de um projeto de edificação adequado
}

\author{
The school environment and the importance of an adequate \\ building project
}

\author{
MAIANA CUNHA ARAÚJO \\ Ma. em Design, UFPE, maianacunha.arq@gmail.com
}

VILMA VILLAROUCO

Dra. em Engenharia, PPGDesign e PPErgo-UFPE, PPGAU+D-UFC, vvillarouco@gmail.com

\section{RESUMO}

Um bom projeto, pensado para sua função, esteticamente agradável e planejado para durar é de grande valor, para qualquer que seja o seu uso final. Mas quando se trata de um projeto para um ambiente escolar sua importância é ainda mais evidente, pois suas características podem interferir positiva ou negativamente sobre o aprendizado. $\mathrm{O}$ ambiente de sala de aula funciona como uma ferramenta que suporta a prática pedagógica, e quando bem pensado, além de ter uma boa atuação como intermediário da atividade, também é sustentável sob a ótica do conforto ambiental. Esta pesquisa teve como principal objetivo identificar os benefícios que uma edificação adequadamente projetada pode trazer para a atividade pedagógica, e para tanto estudou duas escolas públicas da rede estadual de ensino, ambas localizadas na região metropolitana do Recife. A primeira está num edifício adaptado para funcionar como escola, e a segunda teve sua edificação planejada para ser uma escola. A análise dos dois espaços construídos foi feita mediante utilização da Metodologia Ergonômica do Ambiente Construído (MEAC) (VILLAROUCO, 2001) e a investigação da opinião dos usuários foi feita com a aplicação da Constelação de Atributos (EKAMBI-SCHMIDT, 1974). O propósito desta seleção foi demonstrar as diferenças importantes de desempenho geral que um bom projeto, adequadamente pensado, proporciona, podendo ser uma garantia de qualidade de vida para seus usuários.

PALAVRAS-CHAVE: MEAC, sala de aula, conforto ambiental, ambiente construído.

\section{ABSTRACT}

A good design, planned for its function, aesthetically pleasing and designed to last has a great value, whatever its end use. But when it comes to a project for a school environment its importance is even 


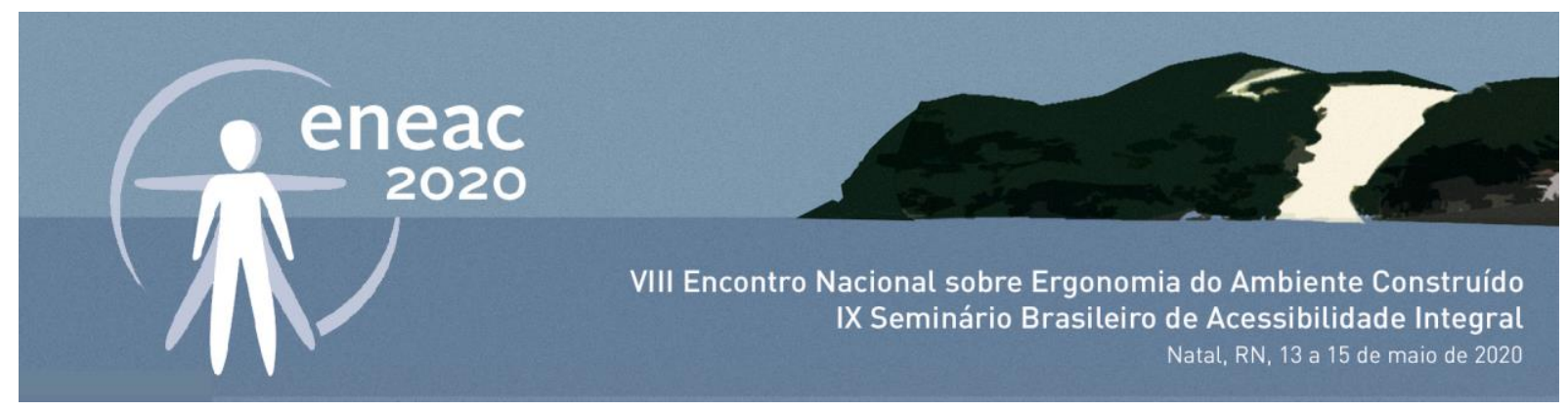

more evident, as its characteristics can positively or negatively interfere with learning. The classroom environment works as a tool that supports pedagogical practice, and when well thought, besides having a good performance as an intermediary of the activity, is also sustainable from the perspective of environmental comfort. This research had as main objective to identify the benefits that a properly designed building can bring to the pedagogical activity, and for that two public schools from the state school system were studied, both located in the metropolitan region of Recife. The first is in a building adapted to function as a school, and the second was planned to be a school. The analysis of the two built spaces was made using the Ergonomic Methodology of the Built Environment (MEAC) (VILLAROUCO, 2001) and the users opinion was investigated by applying the Constellation of Attributes (EKAMBI-SCHMIDT, 1974). The purpose of this selection was to demonstrate the important differences in overall performance that a good design, properly thought out, provides and can be a guarantee of quality of life for its users.

KEYWORDS: MEAC, classroom, environmental comfort, built environment.

\section{INTRODUÇÃO}

O ambiente escolar é um dos lugares onde as pessoas passam longos períodos de tempo, e onde a atividade exercida requer que seu espaço seja bem planejado e executado, de modo que funcione como uma ferramenta que colabora com a construção do aprendizado. Para o estudo deste tipo de ambiente a ergonomia do ambiente construído (EAC) se apresenta como meio mais viável e completo, pois permite a integração de diferentes campos do conhecimento com a finalidade de um diagnóstico preciso e soluções eficientes. Ao colocar o ser humano como foco de seu estudo, a EAC abre espaço para a análise de tudo o que se relaciona com ele, visando principalmente a melhoria da qualidade de vida.

Para tanto, é necessário que a edificação destinada à atividade de ensino seja bem projetada. De acordo com o relatório feito pela Comissão para Arquitetura e Ambiente Construído do Reino Unido, um bom projeto trata de prover edifícios e espaços adequados ao seu propósito, construídos para durar e que elevem os espíritos. Um bom projeto cria espaços seguros, saudáveis e sustentáveis (CABE, 2006). Ainda segundo o mesmo relatório bons projetos não acontecem por acaso, precisam ser planejados para atingirem excelência, e uma das falhas mais comuns neste processo é o pouco envolvimento do usuário final no processo de projeto. Esta informação torna ainda mais evidente a necessidade do uso da EAC tanto na concepção quanto na intervenção em espaços edificados.

No ambiente educativo o bom projeto é fundamental, evidências mostram que o bom projeto de escolas pode promover melhoria da performance, manutenção e retenção da equipe de trabalho e aumento da criatividade e satisfação dos professores quanto ao processo de ensino. Uma pesquisa feita em escolas norte americanas elencou dez fatores relacionados com salas de aula eficientes ou ineficientes, e um deles foi o aspecto da sala de aula (TEDDLIE; KIRBY; STRINGFIELD, 1989), e dados do Centro Nacional de Estatísticas da Educação (NCES) mostram que em escolas com infraestrutura considerada ruim $48 \%$ dos professores pediram transferência, e $39 \%$ trocaram de profissão por considerarem seus ambientes de trabalho degradados (CHANEY et al., 2005). 


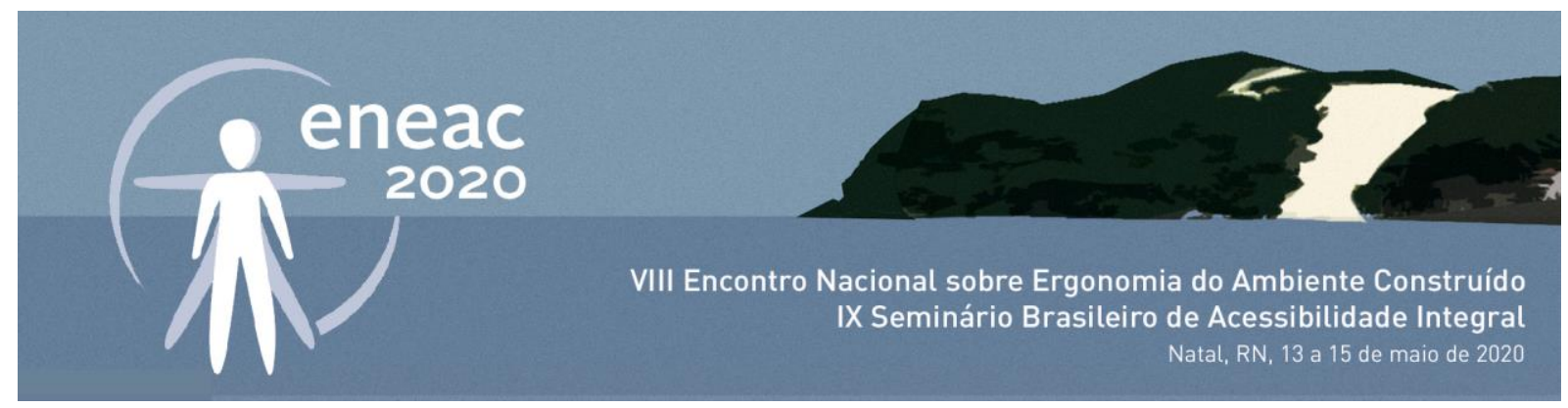

O ambiente pode interferir diretamente sobre o desempenho dos estudantes, sua qualidade transmite não só conforto, mas a mensagem de que a educação daquelas pessoas importa. Rapoport (1982) identificou em seus experimentos que os elementos que compõem o ambiente fornecem "pistas" aos usuários do espaço, transmitem informações sobre status, comportamento, etc. Desta forma, um ambiente escolar bem planejado e mantido comunica indiretamente a seus usuários que a atividade ali exercida merece atenção e cuidado. Em 1997 a Charles Young Elementary School, nos Estados Unidos, fez uma grande reforma em seu edifício levando em conta dados de pesquisas sobre o ambiente construído. As notas dos alunos antes da reforma eram, em média, abaixo do considerado mediano, mas depois da reforma aumentaram a cada ano. Os alunos com notas mais baixas tiveram aumento de cerca de $50 \%$ em suas notas, e $23 \%$ de todos os alunos obtiveram notas acima da média nacional.

Nesta pesquisa foram selecionadas duas instituições públicas de ensino, ambas vinculadas à mesma gerência regional do governo estadual de Pernambuco, e ambas com alunos com mesmo índice socioeconômico, segundo dados do senso escolar de 2017 (INEP, 2019). Uma das escolas está em uma edificação que foi adaptada para funcionar como escola, enquanto a outra foi construída na década de 70 especificamente para ser uma escola para ensino fundamental e médio. As duas escolas foram avaliadas através da aplicação da Metodologia Ergonômica do Ambiente Construído (MEAC) (VILLAROUCO, 2001) e comparadas mediante elaboração do diagnóstico ergonômico. Para a etapa de análise da opinião do usuário, parte da MEAC, foi utilizada a constelação de atributos (EKAMBI-SCHMIDT, 1974). A seleção das duas escolas visou mostrar a necessidade de que o ambiente escolar seja projetado para a sua atividade específica, a fim de garantir qualidade de vida e um bom processo de construção do aprendizado.

\section{FATORES AMBIENTAIS, ATENÇÃO E APRENDIZADO}

A avaliação do conforto ambiental é de suma importância para a EAC, pois são itens que influenciam diretamente a percepção e conforto dos usuários, e consequentemente interferem diretamente na realização das tarefas. Segundo (IIDA, 2005) qualquer ambiente deve ser confortável, porém quando tratamos de ambientes de longa permanência esta condição é imprescindível. A atividade pedagógica envolve um processo prolongado de manutenção da atenção, pois os alunos permanecem nestes espaços por horas, ao longo das quais precisam manter o foco nos estímulos interessantes para o aprendizado em detrimento de outros. De fato, esta definição do que acontece em sala de aula é a própria definição de Sternberg, Costa e Haase (2008) para a atenção, e esta habilidade de sustentar barreiras para estímulos indesejados demanda esforço por parte dos alunos. A manutenção da atenção é vital para o aprendizado, e pode ser facilmente interrompida.

Segundo Rueda (2013), a atenção pode se dividir em 3 tipos: concentrada, dividida e alternada. A atenção concentrada é a capacidade de concentrar-se somente em uma fonte de informação em detrimento de outras, focando somente em uma fonte de estímulo. A atenção dividida consiste na habilidade para concentrar-se em dois ou mais estímulos ao mesmo tempo e a atenção alternada é a capacidade de focar alternadamente em dois ou mais estímulos diferentes, não simultaneamente. 


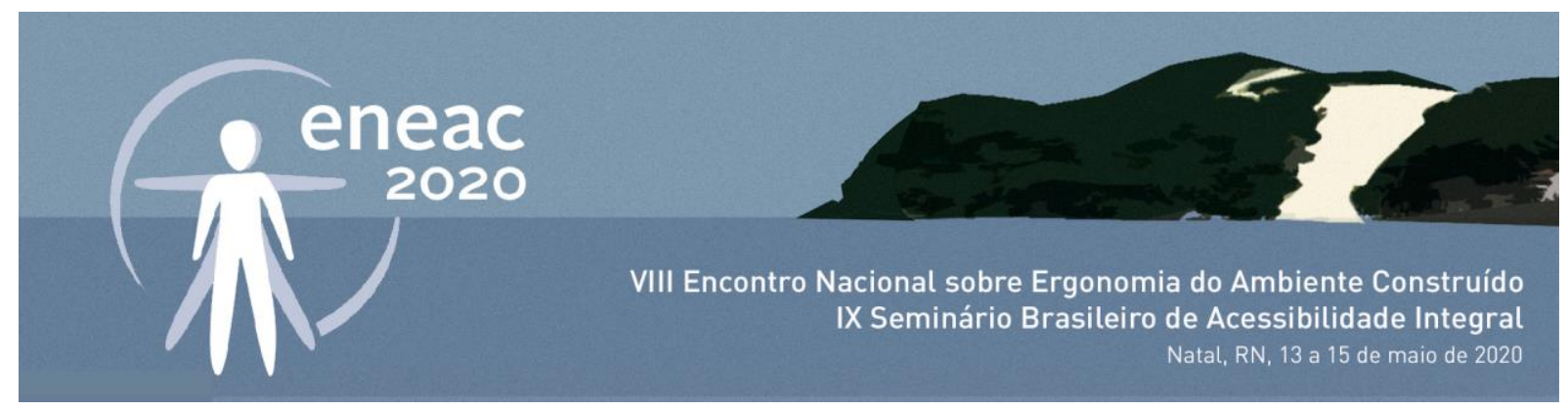

Todos estes tipos participam do processo de aprendizagem, e como um todo são os processos mentais que mais contribuem para a construção do conhecimento, sendo fundamentais para que ela aconteça (CORTEZ et al., 2013; LE PELLEY et al., 2016).

Quando a estrutura escolar tem qualidade inferior ou é mal mantida, os alunos apresentam maior dificuldade em manter o foco, de modo que o ambiente desencoraja o engajamento deles nas atividades escolares, dificulta o processo de sustentação da atenção e ainda diminui o entusiasmo dos professores por seu trabalho (ULINE et al., 2010). O ambiente construído, então, não pode ser entendido como um mero invólucro onde acontecem as atividades educativas, mas sim como um agente impulsionador e motivador para a atividade, uma vez que interfere ativamente nos processos atencionais dos alunos. Segundo Green e Turrel (2005) o ambiente construído influencia o desempenho acadêmico e o comportamento dos estudantes, assim como a saúde e o bem estar de alunos e professores.

Wurtman (1975) diz que a luz é o fator mais importante para o controle das funções corporais, depois da água e a alimentação, e que é interessante que todas as pessoas tenham acesso tanto à luz natural quanto artificial de qualidade durante o dia. Salas de aula pouco iluminadas e sem janelas podem fazer com que os alunos experimentem uma forma diária de jet lag (alteração do ritmo biológico devido a distúrbios dos níveis hormonais), que pode provocar sintomas de fadiga durante o dia e alteração do sono durante a noite (TANNER, 2008). A luz afeta o aprendizado por interferir principalmente sobre o comportamento, o que pode ser observado na pesquisa de Grangaard (1995). O pesquisador observou salas de aula com índices de iluminação adequadas e inadequadas, e naquelas com a luz ideal os alunos apresentaram $24 \%$ menos tempo em comportamentos distratores da tarefa do que nas salas com pouca luz.

A temperatura também é um elemento ambiental muito importante para a qualidade do aprendizado. A pesquisa de Barrett et al (2015) identificou uma significativa melhoria do desempenho dos alunos e diminuição do nível de stress da turma quando a temperatura da sala de aula foi ajustada para níveis considerados adequados. Alunos demonstraram maior satisfação em salas de aula com nível de temperatura adequado e ventilação natural (WARGOCKI; WYON, 2007) e em paralelo apresentaram comportamento mais focado na atividade do que em outras condições térmicas. Nico, Liuzzi e Stefanizzi (2015) afirmam que para que se obtenha padrões interessantes de qualidade e conforto no edifício escolar é preciso investir em sistemas de controle de temperatura, pois a mesma interfere diretamente sobre a concentração e, por consequência, sobre o aprendizado.

A qualidade acústica e o ruído são os elementos ambientais que mais diretamente apresentam consequências físicas em alunos e professores quando não estão adequados. Segundo Penteado e Pereira (2007) professores são a categoria de profissionais que mais apresentam quadros de disfonia (alteração ou enfraquecimento da voz) por constantemente esforçarem-se para superar as inadequadas condições ambientais, além da indisciplina e do ruído causado por salas de aula muito cheias. Em uma pesquisa realizada com professores da rede municipal de ensino foi identificado que, na opinião de $43,3 \%$ desses profissionais, o ruído das sala de aula era elevado ou insuportável como competição sonora ao uso da voz, e $34,4 \%$ disseram que possuem sintomas de disfonia (GOMES; MEDEIROS; TEIXEIRA, 2016). Outra pesquisa também indica que níveis elevados de ruído também 


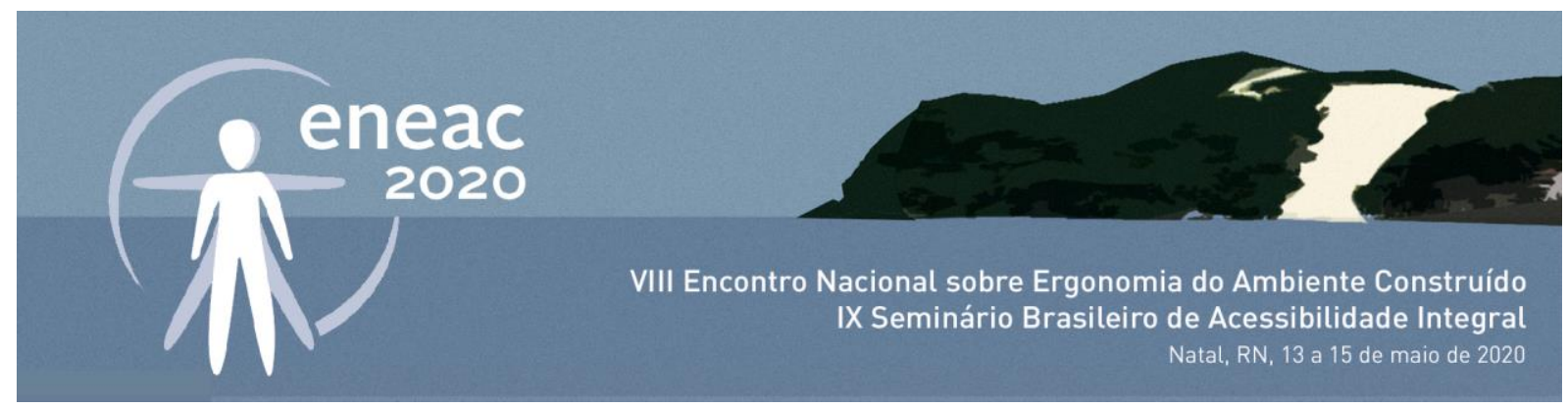

podem prejudicar o desenvolvimento de habilidades de leitura e raciocínio lógico dos alunos (MAXWELL; EVANS, 2000).

Outro fator relevante é o dimensionamento das salas de aula. Salas com um elevado número de ocupantes ignoram as chamadas distâncias sociais, que são espaços formados no subconsciente do indivíduo que condicionam o seu comportamento em situações sociais públicas ou de intimidade (ALEXANDER; ISHIKAWA; SILVERSTEIN, 1977). Pouco espaço condiciona a invasão dessas distâncias, de modo que provoca uma influência negativa sobre os alunos (TANNER, 2008). Como já mencionado, o ambiente construído transmite a seus ocupantes "mensagens", e o espaço da sala de aula tem um teor bastante social, onde o fluxo e os deslocamentos são grande parte do processo de comunicação (DUNCANSON; VOLPE; ACHILLES, 2009).

O relatório "The impact of school environments: a literature review", desenvolvido para o conselho de projeto do centro de aprendizado e ensino da Universidade de Newcastle, Reino Unido, afirma que os projetos de sala de aula contemporâneos estão subdesenvolvidos, pois baseiam-se na premissa de que um formato adequa-se a todas as necessidades do ensino (HIGGINS et al., 2005). 0 mesmo relatório afirma que se sabe muito sobre temperatura, ruído e iluminação isoladamente, mas que pouco se sabe sobre o quanto cada fator desse impacta o aprendizado, e portanto estudar e aprimorar este tipo de ambiente é necessário e urgente. A melhoria do ambiente de sala de aula implica não somente na melhoria da qualidade de vida de seus ocupantes, o que já seria razão para ser estudado, mas representa a melhoria do aprendizado e do futuro das novas gerações.

\section{MÉTODOS UTILIZADOS}

Para esta pesquisa foram selecionadas duas escolas públicas estaduais, sendo que uma funciona em uma edificação antiga, adaptada para ser uma escola, enquanto que outra funciona em um edifício que foi construído para ser aquela escola. As duas instituições estão sob a mesma gerência regional do estado de Pernambuco, e por solicitação desta gerência e das equipes gestoras das próprias escolas seus nomes não serão divulgados, de modo que a escola que funciona no edifício adaptado será a Escola 1 e a outra, Escola 2. Também nas duas escolas funcionam turmas do ensino fundamental I, e por uma questão de recorte, foram entrevistados 15 alunos de cada turma de nono ano de cada escola, totalizando 60 entrevistados.

Para análise do ambiente foi utilizada a Metodologia Ergonômica do Ambiente Construído (MEAC) desenvolvida pela professora Vilma Villarouco (VILLAROUCO, 2001). Este método abrange 4 etapas de análise e uma de diagnóstico e recomendações. A primeira etapa é a análise global do ambiente, que é o primeiro contato do pesquisador com o local a ser analisado e é quando identificam-se as características e peculiaridades do local (mapa, área, histórico, horário de funcionamento, etc.), a estrutura organizacional, identificação dos usuários, compreensão dos processos de trabalho, dinâmica da instituição, etc. Ela permite ao pesquisador planejar as próximas etapas, e por isso precisa ser tão abrangente. 


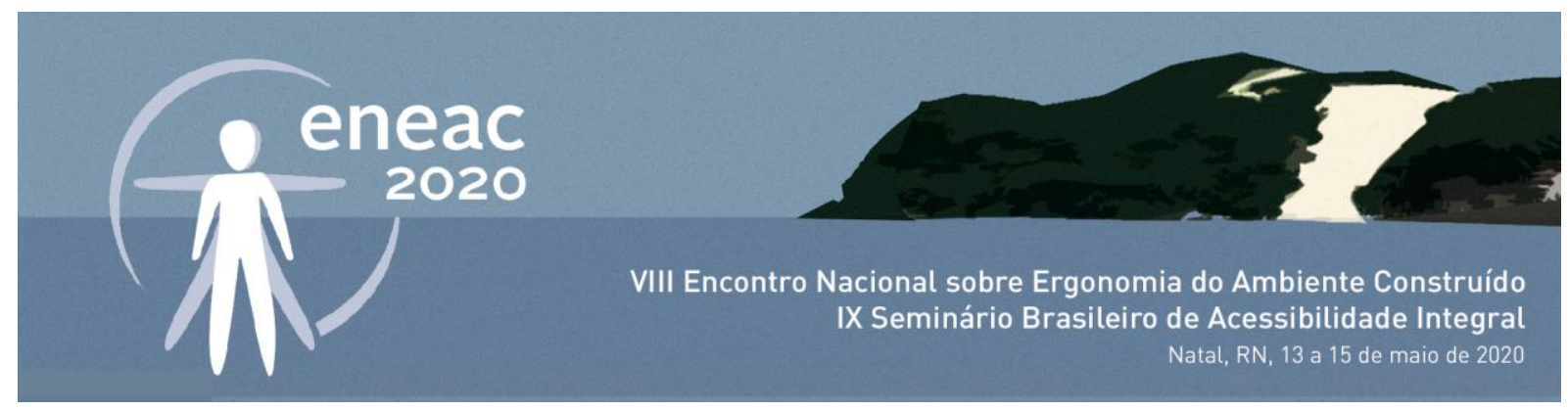

A segunda etapa é a identificação da configuração ambiental, onde é feita a análise da tarefa ao mesmo tempo em que se conhece com mais detalhe as condições físicas do espaço. Nela deve conter a descrição detalhada da estética do ambiente, o registro de imagens do ambiente, o registro da planta baixa atualizada, assim como cortes e elevações, quadro de áreas, descrição de mobiliários e equipamentos e nesta etapa é quando são feitas as medições dos índices de conforto ambiental.

A terceira etapa é a avaliação do ambiente em uso, que consiste na observação dos usuários no desempenho das atividades. É quando é feita a descrição da relação entre as atividades e o ambiente, a análise dos fluxos e deslocamentos e entrevistas com os usuários para maior compreensão do cenário. É necessário que esta etapa aconteça após o levantamento dos dados físicos do ambiente, para que a observação seja mais precisa e seu registro mais realista.

A quarta etapa, a análise da percepção do usuário, acontece com o auxílio de uma ferramenta de investigação da opinião do usuário, que neste caso contará com a constelação de atributos. Idealizada por Moles, em 1968 e desenvolvida por Ekambi-schmidt (1974), a constelação é uma ferramenta de psicologia ambiental que organiza graficamente as opiniões emitidas pelos entrevistados de forma sintética e ordenada. Consiste numa entrevista com duas perguntas, onde na primeira identifica-se a opinião do usuário sobre um ambiente imaginário, ideal, similar ao seu. Nesta pesquisa a pergunta utilizada foi "quando você pensa numa sala de aula, quais conceitos e ideias vem à sua mente?". Na segunda, identifica-se a opinião do usuário sobre a sua sala de aula, e nesta pesquisa a pergunta utilizada foi "quando você pensa na sua sala de aula, quais conceitos e ideias vem à sua mente?". Os resultados foram organizados em 2 gráficos que permitiram compreender como os estudantes percebem suas salas de aula. Por se tratar de uma entrevista com usuários, esta pesquisa foi submetida à análise e aprovada pelo Comitê de Ética em Pesquisa (CEP) da UFPE.

O Diagnóstico ergonômico do ambiente e recomendações é a quinta e última etapa da MEAC. Nela é quando é feito o cruzamento dos dados obtidos, sua análise e conseguinte diagnóstico, resultando num relatório abrangente que retrata toda a análise das etapas anteriores, assim como normas e leis específicas adotadas como critério de avaliação. $O$ diagnóstico propõe melhorias para o ambiente com foco no usuário e na atividade, visando melhoria da qualidade de vida e aumento da eficiência do trabalho realizado. É a etapa que sintetiza tudo o que foi analisado.

Nesta pesquisa, foram utilizados como critérios de qualidade para os índices de conforto ambiental aqueles definidos pelas seguintes normas: Norma de Higiene Ocupacional 11 (NHO11) (CUNHA et al., 2018) para a iluminação, a NBR 5192:1999 para o ruído (ASSOCIAÇÃO BRASILERA DE NORMAS TÉCNICAS - ABNT, 1999) e para a análise da acessibilidade foi utilizada a NBR 9050:2015 (ASSOCIAÇÃO BRASILEIRA DE NORMAS TÉCNICAS - ABNT, 2015). A Norma Regulamentadora 17 (NR17) (BRASIL, 2007) foi utilizada como referência para método de medição da temperatura e velocidade do ar, porém por uma questão de adequação à percepção ambiental dos alunos em regiões quentes e úmidas os valores de referência adotados foram os de lida (2005). Para as medições dos fatores de conforto ambiental foram utilizados o decibelímetro Pyle PSPL03, o termoanemômetro CE Nº 201506007198 e o luxímetro Dr Meter LX1330B.

A finalidade da seleção de duas edificações, sendo uma adaptada e uma originalmente pensada para ser uma escola foi comprovar que um bom projeto, mesmo antigo e com alguma deficiência em sua 


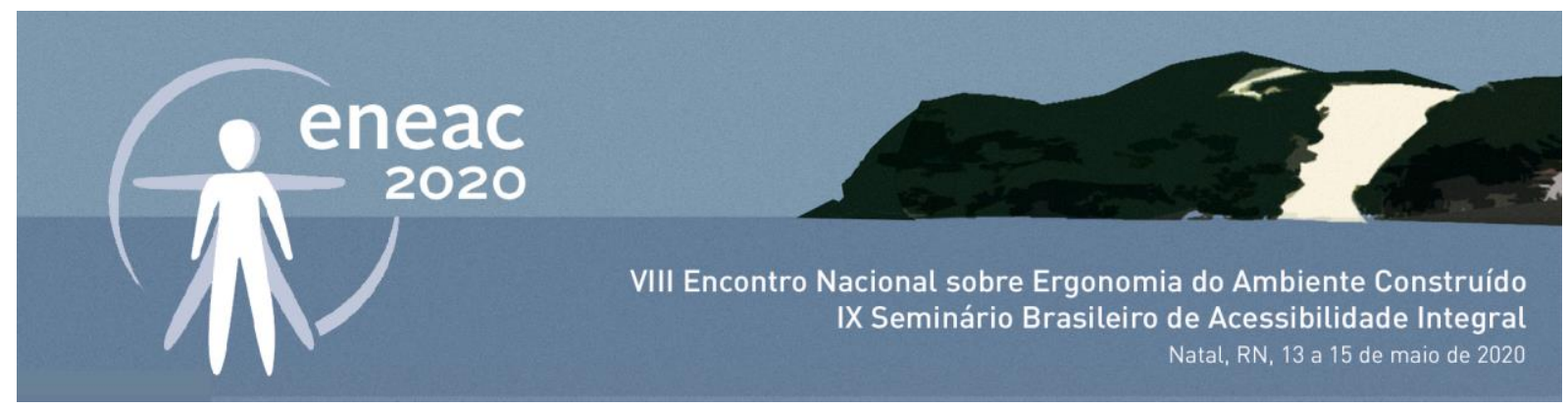

preservação, garante a seus usuários conforto e melhor qualidade de vida, e incluir a ótica da ergonomia é fundamental por levar em conta a execução da atividade pedagógica e tudo o que isto implica, além de incluir a análise da opinião dos usuários, que é o público que melhor conhece o ambiente.

\section{PESQUISA DE CAMPO}

As duas escolas selecionadas funcionam na região metropolitana do Recife, Pernambuco, e suas aulas acontecem nos turnos da manhã (das 7:30h às 11:40h) e da tarde (das 13:30h às 17:40h). Uma delas funciona num edifício antigo, que foi adaptado para funcionar como escola (Escola 1), a outra funcionava também num edifício adaptado, mas na década de 70 mudou-se para o endereço atual, um edifício que foi construído especificamente para ela (Escola 2). A pesquisa foi realizada ao longo de 15 dias em cada instituição, totalizando um mês. Ao início de cada etapa da investigação a equipe gestora foi informada dos procedimentos a serem adotados, e tudo o que foi documentado foi apresentado a ela ao final de cada etapa. As duas escolas possuem nível socioeconômico 4,6, considerado médio-baixo segundo as categorias do censo (INEP, 2019), assim como $72 \%$ das escolas estaduais do Recife. Essa característica foi importante para demonstrar a equivalência de condições dos aspectos socioeconômicos dos usuários das escolas (SIQUARA, 2014).

\subsection{Aplicação da MEAC}

A escola 1 funciona em um edifício datado do final do século XIX, tombado, e adaptado para o uso atual. Conta com 20 educadores, 11 funcionários e 318 alunos do $5^{\circ}$ ao $9^{\circ}$ ano. De forma geral a edificação é acessível, pois existem rampas que permitem acesso à área administrativa, porém as salas e banheiros não são acessíveis. Todo o espaço possui pé-direito com 4,5m de altura em média, e todas as salas possuem forro de madeira antigo, que eventualmente se solta e traz riscos aos usuários das salas. As portas e esquadrias também são em madeira antiga, o que faz com que algumas não abram com facilidade, principalmente as janelas, dificultando a ventilação. Ainda no quesito ventilação, os ventiladores utilizados nas salas também possuem problemas devido à falta de manutenção e muitos não funcionam.

Figura 1: Sala de aula da escola 1.

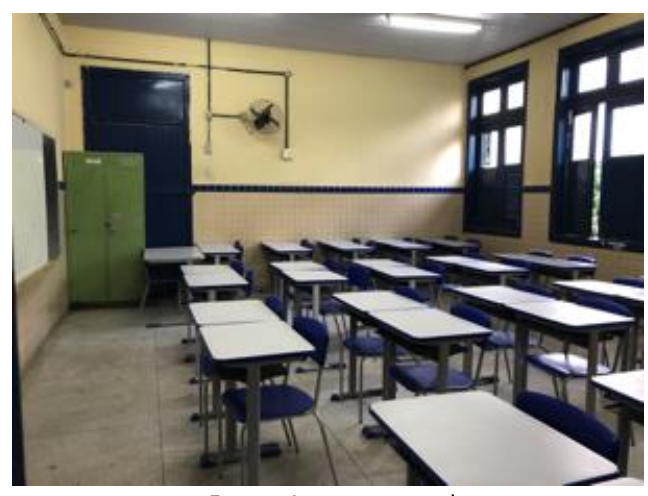

Fonte: Acervo pessoal. 


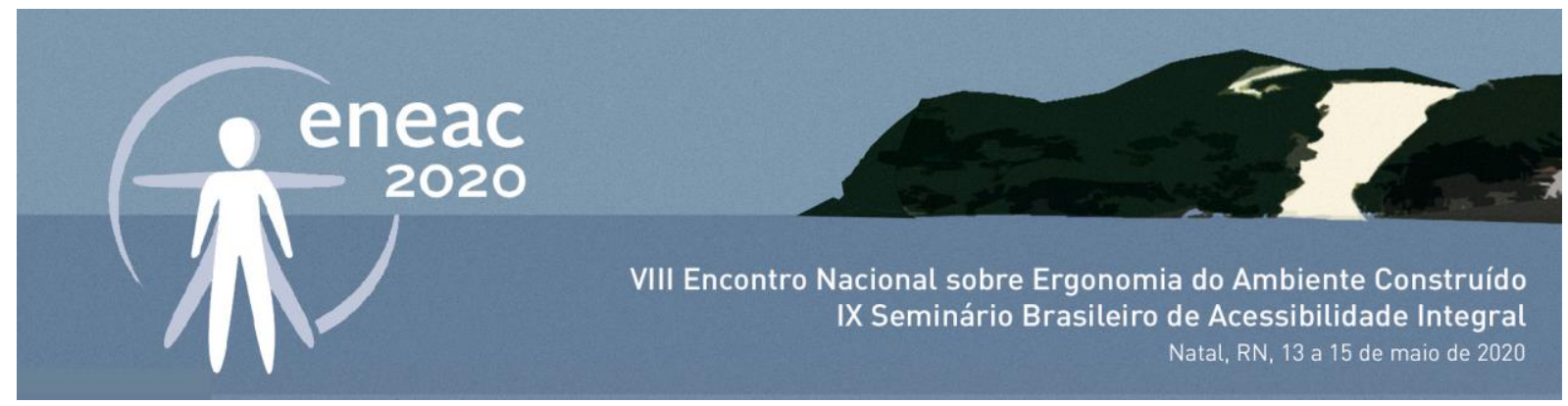

O mobiliário é novo e bem conservado (figura 1), porém as salas são muito cheias, o que dificulta o deslocamento entre as mesas e cadeiras, apesar do número total de alunos não ser considerado grande pelos gestores, que inclusive acusam esta característica como uma dos benefícios desta escola: o reduzido número de alunos permite um acompanhamento mais próximo de cada um. Alguns itens recomendados pelo MEC não constam nesta escola, como o laboratório de informática, de ciências, sala de leitura e sala para atendimento especial.

A escola 2, como já dito, funciona desde a década de 70 em um edifício feito especificamente para ela. Conta com 48 educadores, 15 funcionários e 866 alunos distribuídos do $5^{\circ}$ ao $9^{\circ}$ ano do ensino fundamental. A escola não possui quadra poliesportiva, mas utiliza a quadra que existe na praça em frente à escola, que tem as dimensões corretas. Apesar de ter sido pensada para ser uma escola, a edificação não respeita as demandas para ser considerada acessível. Um cadeirante consegue acessar o bloco de salas da gestão, mas não se desloca com facilidade nos demais ambientes, além de não haver nenhum banheiro acessível.

Figura 2: Sala de aula da escola 2.

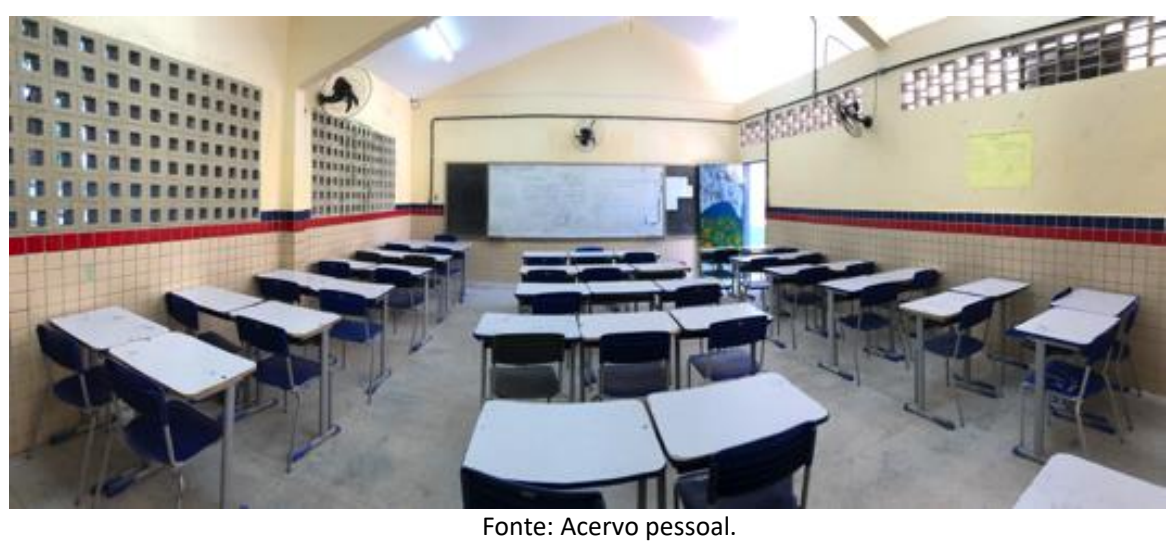

De forma geral, a escola apresenta aspecto construtivo simples, com pé-direito em média de 3,5m nas salas de aula. As portas são de madeira, mas se apresentam bem conservadas e com bom funcionamento, e todas as salas apresentam, ao invés da utilização de janelas, grandes áreas de cobogós sempre em duas paredes opostas, permitindo a ventilação cruzada (figura 2). As salas mais concentradas no poente possuem aberturas maiores, que permitem uma ventilação melhor. Todo o lado poente da edificação conta com terraços cobertos que propiciam uma grande área de sombra nas salas, evitando que o sol da tarde aqueça seus ambientes.

As medições de campo evidenciam o benefício do projeto da escola 2, pois na escola 1 a temperatura média das salas foi de $25,53^{\circ} \mathrm{C}$ pela manhã e de $27,37^{\circ} \mathrm{C}$ à tarde, acima dos $24^{\circ} \mathrm{C}$ recomendados, enquanto que na escola 2 a temperatura média foi de $24,05^{\circ} \mathrm{C}$ de manhã e $25,5^{\circ} \mathrm{C}$ à tarde. $\mathrm{A}$ velocidade do ar também contribui para o conforto térmico, sendo que na escola 1 foi de $0,69 \mathrm{~m} / \mathrm{s}$ de manhã e $0,74 \mathrm{~m} / \mathrm{s}$ à tarde, e na escola 2 foi de $1,42 \mathrm{~m} / \mathrm{s}$ de manhã e $1,37 \mathrm{~m} / \mathrm{s}$ à tarde, valores acima do valor de referencia de $0,2 \mathrm{~m} / \mathrm{s}$ definido por lida (2005). Em resumo, no quesito temperatura, a escola 2 apresenta valores mais próximos ao ideal, e apesar de possuir ventos mais intensos que na 


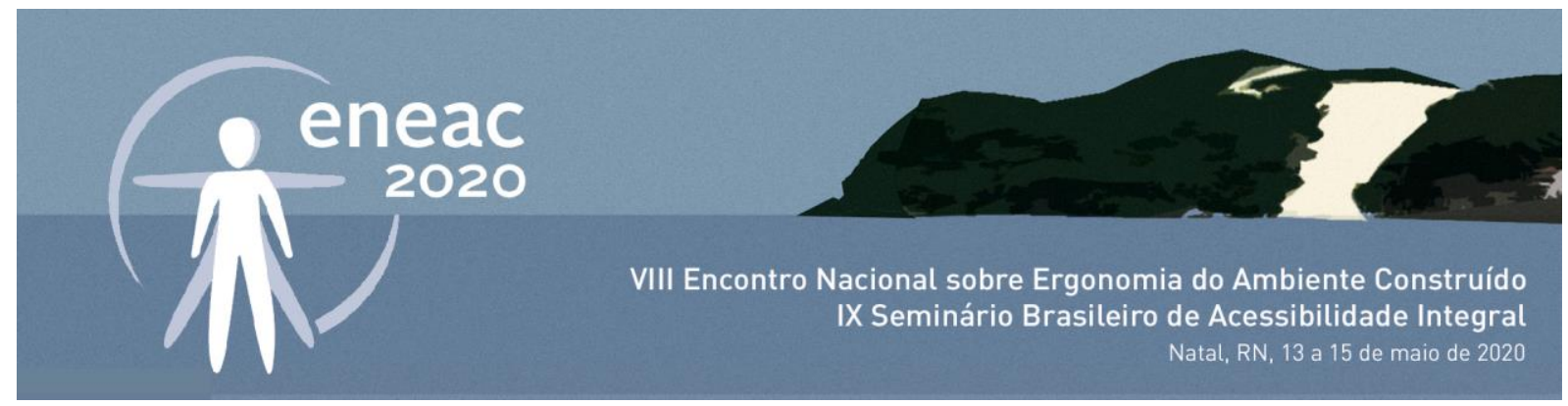

primeira escola, acredita-se que esta condição facilita que seus alunos se sintam confortáveis quanto à temperatura.

No quesito ruído, as duas escolas apresentam-se dentro do considerado ideal para salas de aula, entre $35 \mathrm{~dB}$ e $45 \mathrm{~dB}$, sendo de 35,9dB pela manhã na escola 1 e 36,6dB à tarde, e na escola 2 foi de $29,71 \mathrm{~dB}$ de manhã e $31,05 \mathrm{~dB}$ à tarde, porém foi relatado pelos alunos que o ruído oriundo das outras salas de aula causa incômodo. A iluminação também é um item que mostrou-se adequando nas duas escolas quando se trata de valor médio, pois o valor ideal é de não menos que 300 lux em toda a sala (sendo 403,63Lux de manhã e 354,83Lux de tarde na escola 1 e 605,17 Lux de manhã e 612,90 Lux de tarde na escola 2). Entretanto, a distribuição da iluminação na escola 2 é bem uniforme para todas as salas, variando em média cerca de $18 \%$ dentro de uma mesma sala, enquanto que na escola 1 a variação chega a ser de 72\%, maior que o máximo de $70 \%$ recomendados pela norma.

O dimensionamento das salas é outro fator preocupante, pois segundo Ramos (2010) o número máximo de alunos por turma de ensino fundamental deve ser de trinta por professor, numa área de $45 \mathrm{~m}^{2}$, e nas duas escolas a ocupação média por salas é de 40 a 42 alunos, em salas que medem $43 \mathrm{~m}^{2}$ em média. $\mathrm{O}$ alto número de alunos por turma interfere sobre o comportamento dos estudantes, que se tornam mais agitados (WOHLWILL; VLIET, 1985) além de dificultar o acompanhamento do professor, que não consegue dar a devida atenção a cada estudante (QUEIROZ, 2015).

Gráfico 1: Escola 1, ambiente imaginário.

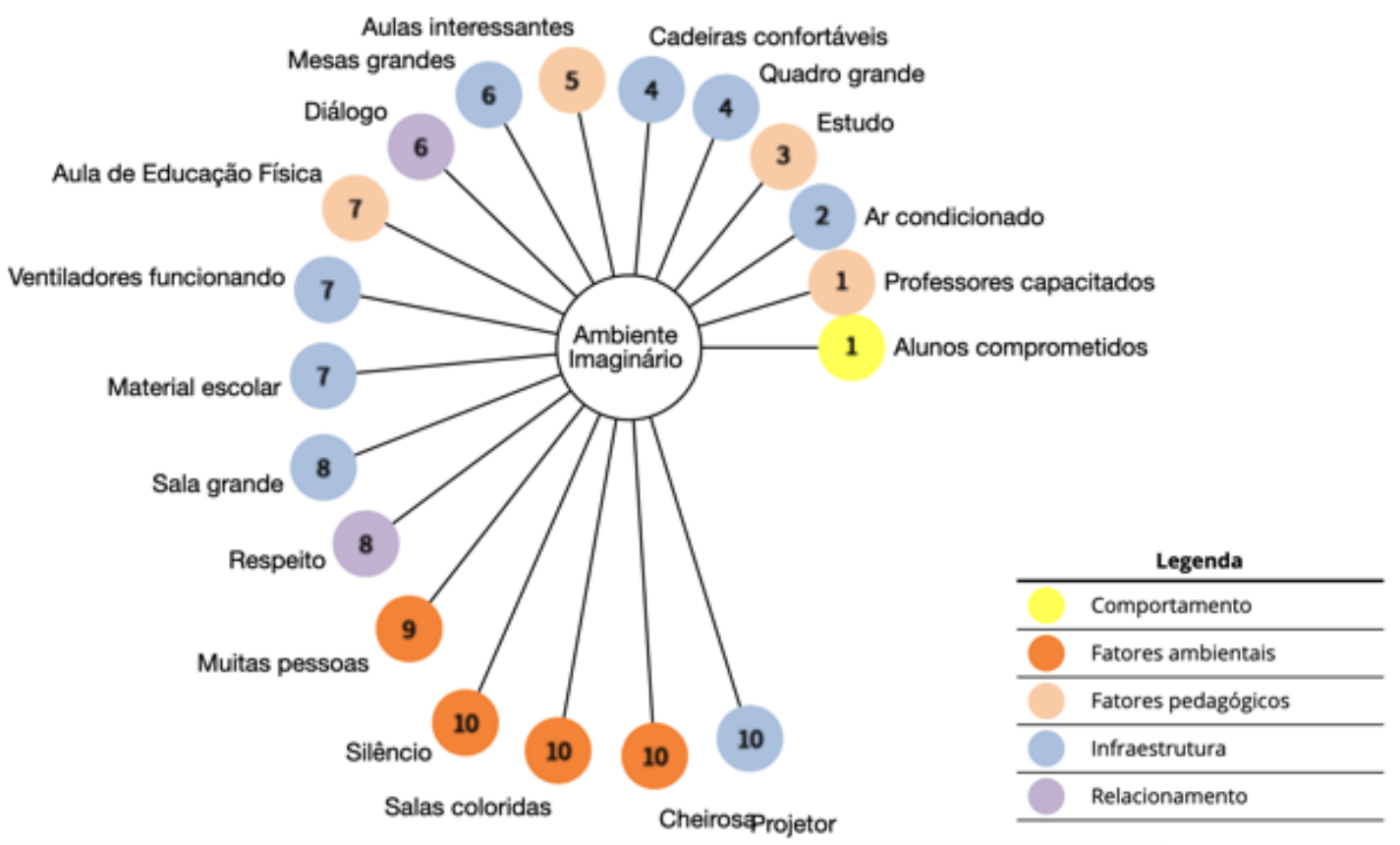

Fonte: Elaborado pelas autoras. 


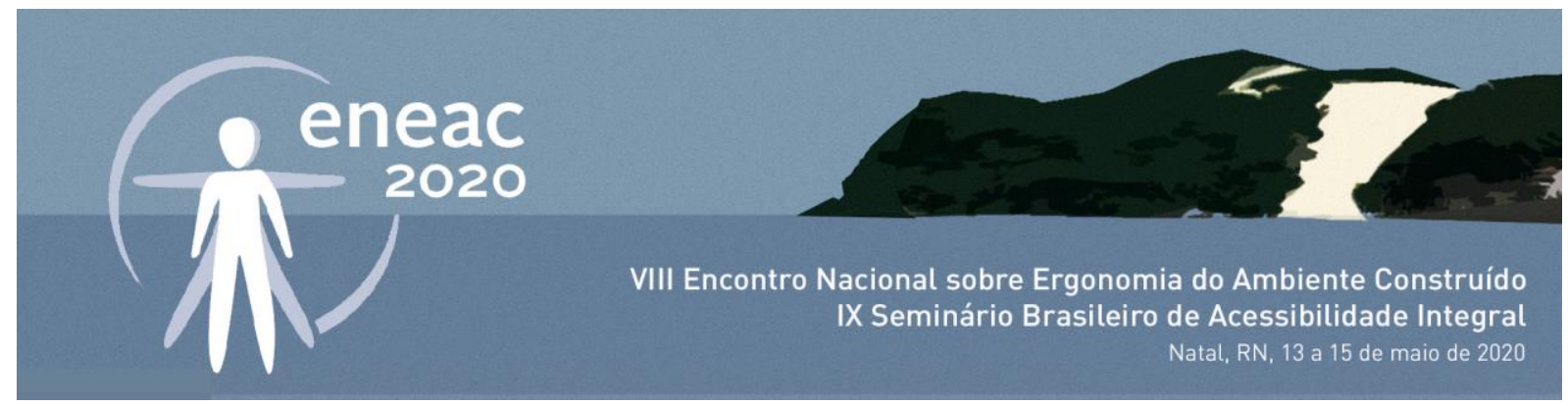

Gráfico 2: Escola 2, ambiente imaginário.

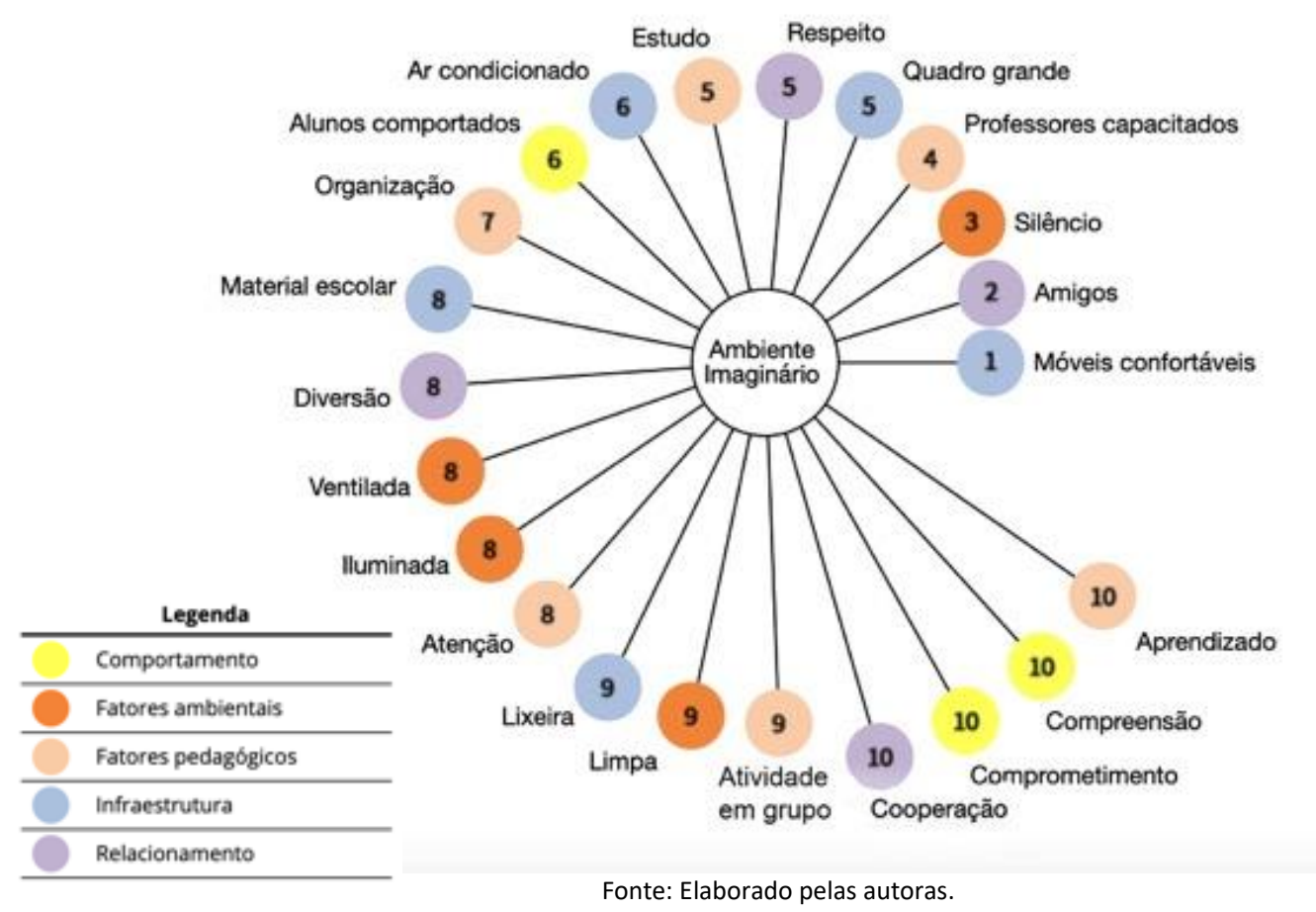

A etapa de investigação da opinião do usuário contou com a participação de 15 alunos de cada turno de cada escola, totalizando 60 participantes selecionados pelas respectivas equipes gestoras. $\mathrm{A}$ primeira pergunta, referente ao ambiente imaginário ("Quando você pensa numa sala de aula, quais conceitos e ideias vem à sua mente?"), trouxe como três primeiros elementos mais importantes para a escola 1 itens como "alunos comprometidos", "professores capacitados" e "ar condicionado". Dentre os 19 atributos mencionados por esses alunos, 8 foram relativos à questões infra estruturais como "sala grande" e "ventiladores funcionando", o que representa $42 \%$ dos itens considerados ideais para uma sala de aula (gráfico 1). Já na escola 2 os atributos gerados para o ambiente ideal foram 22, dos quais apenas 5 tem relação com itens de infraestrutura (22\%), onde os 3 mais representativos foram "móveis confortáveis", "amigos" e "silêncio" (gráfico 2).

Na etapa dos atributos referentes ao ambiente real, (referente à pergunta "Quando você pensa na sua sala de aula, quais conceitos e ideias vem à sua mente?") os alunos da escola 1 avaliaram como mais representativos os fatores "Barulho", "Professores pedindo silêncio" e "Alunos indisciplinados" (gráfico 3). Os 3 fatores batem muito com o fato de que as salas possuem mais alunos do que comportam, o que provoca alterações indesejadas de comportamento, e demonstram a necessidade de investimento em melhoria da acústica ambiental. Nesta escola, dentre os 16 atributos mencionados, 6 são relativos a questões infra estruturais. Na escola 2 os três atributos mais representativos foram "Bagunça", "Amigos" e "Brigas", e somente 2 de 17 elementos mencionados referem-se a elementos do ambiente físico, permitindo inferir a sua boa qualidade (gráfico 4). 

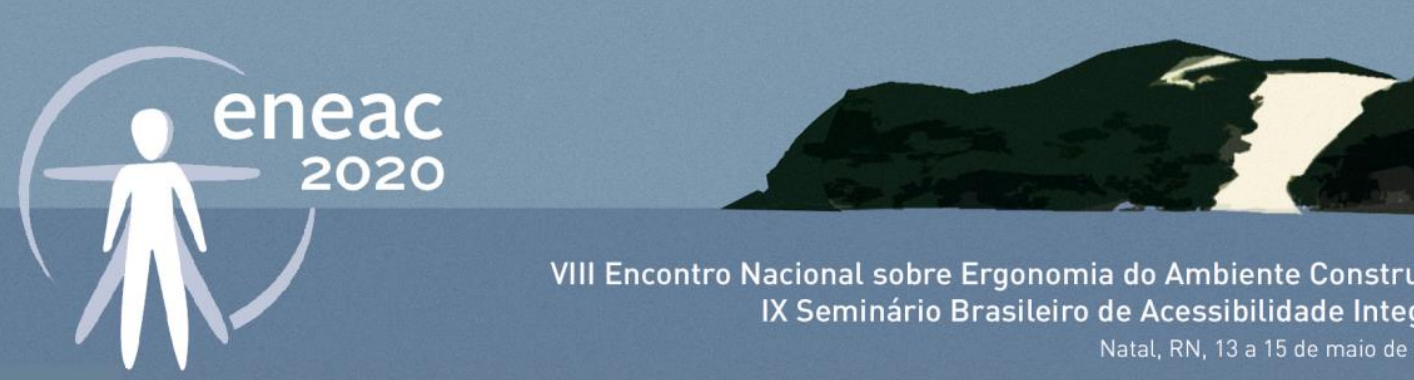

VIII Encontro Nacional sobre Ergonomia do Ambiente Construído IX Seminário Brasileiro de Acessibilidade Integral Natal, RN, 13 a 15 de maio de 2020

Gráfico 3: Escola 1, ambiente real.

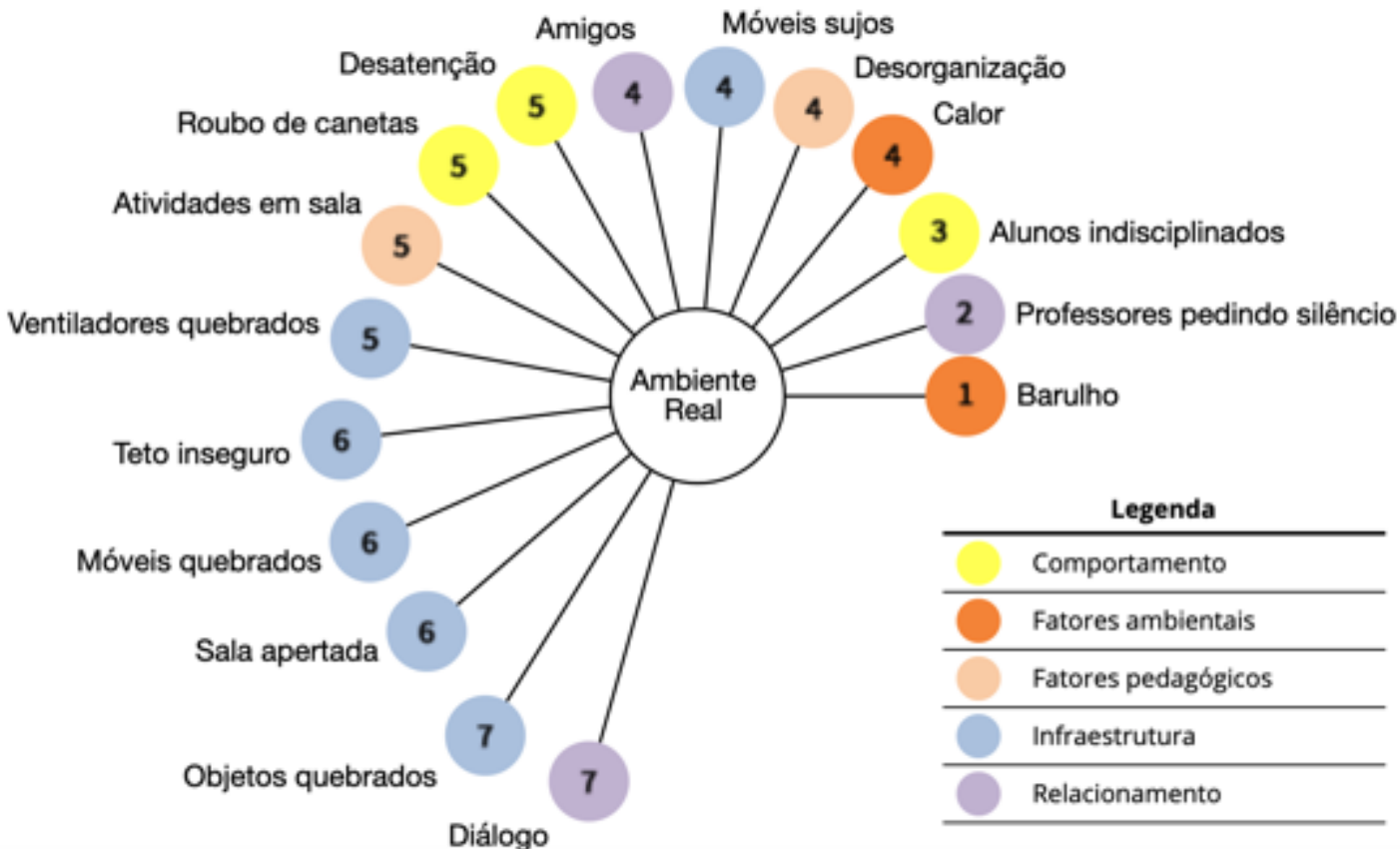

Fonte: Elaborado pelas autoras.

Gráfico 4: Escola 2, ambiente real.

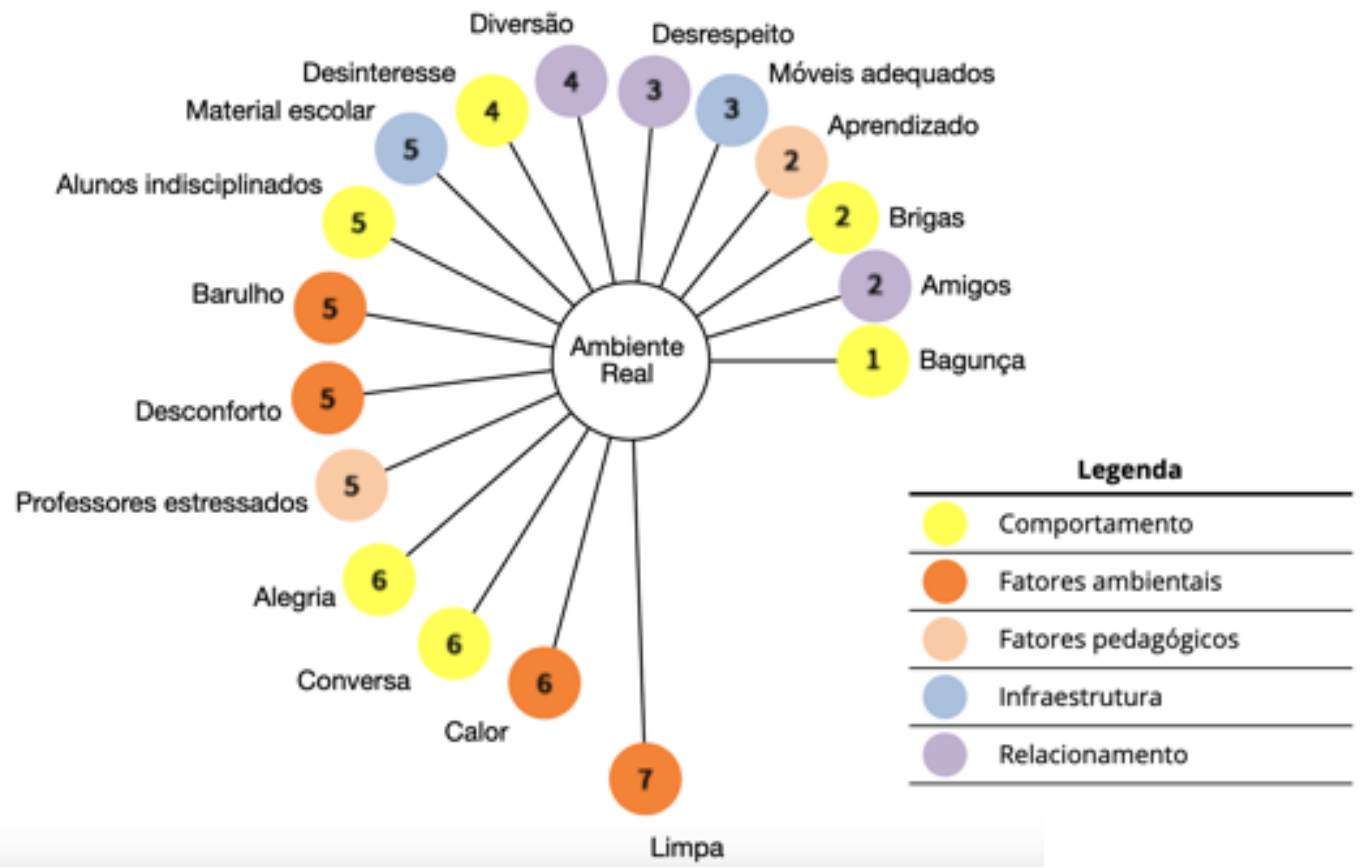

Fonte: Elaborado pelas autoras. 


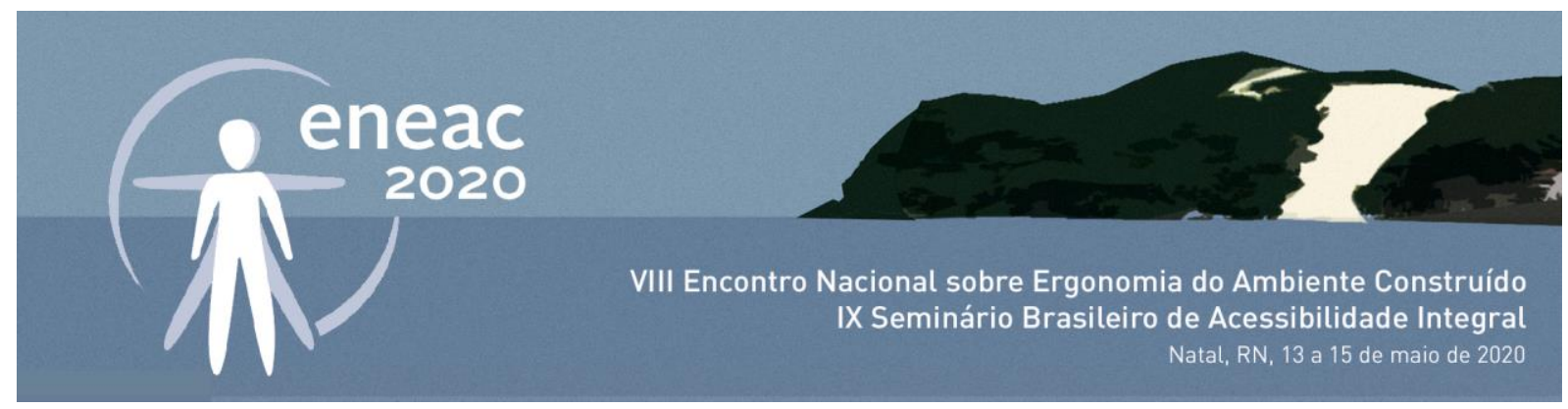

Diante do apurado, as propostas de intervenção relatadas no diagnóstico ergonômico foram categorizadas em de curto, médio e longo prazo. Na escola 1, as soluções de curto prazo consistiram na melhoria da temperatura através da instalação de equipamentos de ar condicionado, pois a forma como foi projetada e o fato de ser tombada impede que sejam feitas alterações em sua estrutura. As soluções de médio prazo tratam da reforma das salas para que utilizem revestimentos que diminuam a reverberação do som, assim como o ajuste dos banheiros para que haja, pelo menos, uma unidade acessível. Este último ajuste que se vincula à uma das soluções de longo prazo, que seria a diminuição do número de alunos por sala, viabilizando a utilização de mobiliário acessível e utilização da escola por pessoas com deficiência.

Na escola 2 as propostas de curto prazo consistem na instalação de cobertas em algumas áreas dos pátios internos, para melhorar suas condições de uso, e reforma das salas para utilização de revestimentos que diminuam a reverberação, melhorando o problema da interferência do ruído de uma sala sobre outra. A médio prazo recomenda-se a adaptação de algumas portas para que tenham a largura recomendada pela NBR 9050, e o ajuste dos banheiros para que haja pelo menos uma unidade nas dimensões consideradas acessíveis. A longo prazo, recomenda-se o mesmo que à escola 1: a diminuição do número de alunos por turma, o que auxiliaria nas questões de comportamento, acompanhamento dos professores e geração de ruído.

De forma geral, observou-se que os ambientes da escola 2, projetados para ter ventilação cruzada, iluminação adequada e uniforme, e terraços que protegem suas paredes do sol poente garantiram a esta instituição salas agradáveis e fáceis de manter (pois não demandam equipamentos de ar condicionado ou outros sistemas) nos últimos 40 anos, enquanto que a escola 1, além de enfrentar problemas de conservação (pela idade do edifício) ainda apresenta condições de conforto ambiental desfavoráveis à prática pedagógica.

\section{Considerações finais}

Um projeto de edificação bem pensado e bem executado, além de garantir melhor qualidade de vida a seus ocupantes, é sustentável. A escola 2 tem sua construção datada da década e 70 e, apesar de apresentar alguns problemas de conservação, possui salas de aula adaptadas às condições climáticas locais. O uso dos cobogós, da ventilação cruzada, dos terraços nos lados voltados para o poente, assim como o bom planejamento de seu sistema de iluminação e bom dimensionamento das salas (adequadas para a quantidade de alunos recomendada para turmas do ensino fundamental) garantiram que durante os últimos quase 50 anos seus alunos desfrutassem de um ambiente com boa iluminação natural e artificial, boa temperatura fruto de ventilação cruzada e espaços bem dimensionados para seus respectivos usos.

Essa qualidade se mostra percebida (ou, pelo menos, de forma inconsciente) quando se observam as respostas desses alunos às questões da constelação de atributos. Na escola 1 os alunos demonstram mais atenção e insatisfação com as questões infra estruturais do que na escola 2. Nesta última, ao ponderar sobre seu próprio ambiente de sala de aula, os alunos citaram somente 2 atributos ambientais, e estes não figuram entre os mais citados. Segundo o censo realizado junto com a Prova 


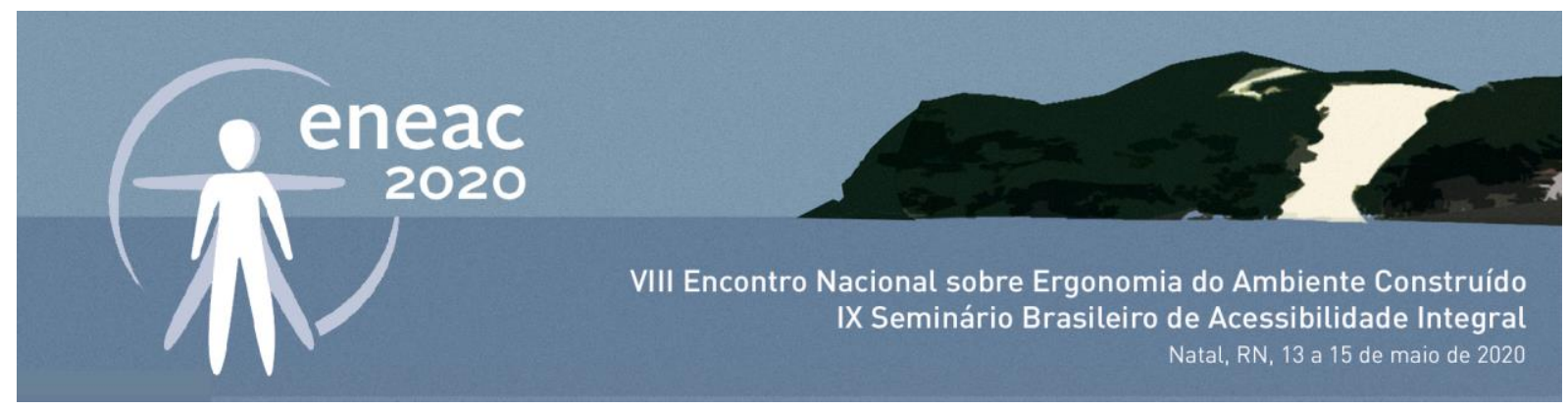

Brasil em 2017, 51\% dos professores de Recife acreditam que a infra estrutura escolar deficiente é responsável pela dificuldade de aprendizagem dos alunos (INEP, 2019).

Uma pesquisa feita com alunos de escolas do Reino Unido com idades entre 5 e 18 anos verificou que ambientes confortáveis e bem dimensionados combinados com uma estética agradável interferem positivamente sobre a concentração, comportamento e motivação dos alunos, além de proporcionarem satisfação e bem estar aos professores (GREEN; TURREL, 2005). Outra pesquisa, também no Reino Unido, classificou 34 salas de aula como "melhores" ou "piores" de acordo com critérios de conforto ambiental, flexibilidade do espaço e preferencia dos alunos. Dentre as 751 crianças acompanhadas, aquelas que utilizavam as salas classificadas como "melhores" apresentaram em média um desempenho $25 \%$ melhor em interpretação de texto e matemática do que os alunos que utilizavam as demais salas (BARRETT et al., 2013).

Estes estudos reforçam e evidenciam a necessidade de compreender o ambiente de sala de aula como uma ferramenta que colabora com a atividade pedagógica, e que portanto precisa ser bem planejada e executada, além de merecer ser algo de pesquisas para constante aprimoramento. É preciso abandonar a prática de adaptar quaisquer espaços com muitas salas de aula para que se tornem escolas, é preciso compreender que um único modelo de sala não atende a todas as práticas. A sala de aula não é um invólucro onde a aula acontece, é um elemento que pode e deve ser usado para a melhoria da qualidade de vida de alunos e professores. E o estudo aqui realizado demonstra que o investimento em bons projetos, que levam em conta clima e condições naturais do entorno onde a escola será implantada garante conforto ambiental sustentável.

\section{REFERÊNCIAS}

ALEXANDER, C.; ISHIKAWA, S.; SILVERSTEIN, M. A pattern language. Nova Yorque: Oxford University Press, 1977.

ASSOCIAÇÃO BRASILEIRA DE NORMAS TÉCNICAS - ABNT. Acessibilidade a edificações, mobiliário, espaços e equipamentos urbanosBrasil, 2015. Disponível em: <www.abnt.org.br>

ASSOCIAÇÃO BRASILERA DE NORMAS TÉCNICAS - ABNT. Acústica - Avaliação do ruído em áreas habitadas , visando o conforto da comunidade - ProcedimentoBrasil, 1999.

BARRETT, P. et al. A holistic, multi-level analysis identifying the impact of classroom design on pupils' learning. Building and Environment, v. 59, p. 678-689, jan. 2013.

BARRETT, P. et al. The impact of classroom design on pupils' learning: Final results of a holistic, multi-level analysis. Building and Environment, v. 89, p. 118-133, jul. 2015.

BRASIL. Norma Regulamentadora 17: ergonomiaDiário oficial da união de 26/06/07Brasil, 2007. Disponível em: <http://www.guiatrabalhista.com.br/legislacao/nr/nr17.htm>

CABE, C. FOR A. AND THE B. E. Better public building. Londres: [s.n.]. Disponível em: <www.cabe.org.uk>

CHANEY, B. et al. Statistical Analysis Report Public School Principals Report on Their School Facilities: Fall 2005 Public School Principals Report on Their School Facilities: Fall 2005 Statistical Analysis Report. 2005.

CORTEZ, R. et al. O desenvolvimento dos mecanismos atencionais em estudantes brasileiros do ensino fundamental. Avances en Psicología Latinoamericana, v. 31, n. 1, p. 165-180, 2013.

CUNHA, I. DE Â. et al. Norma de Higiene Ocupacional 11: Avaliação dos níveis de iluminamento em ambientes internos de trabalhoSão PauloFundacentro, , 2018. 


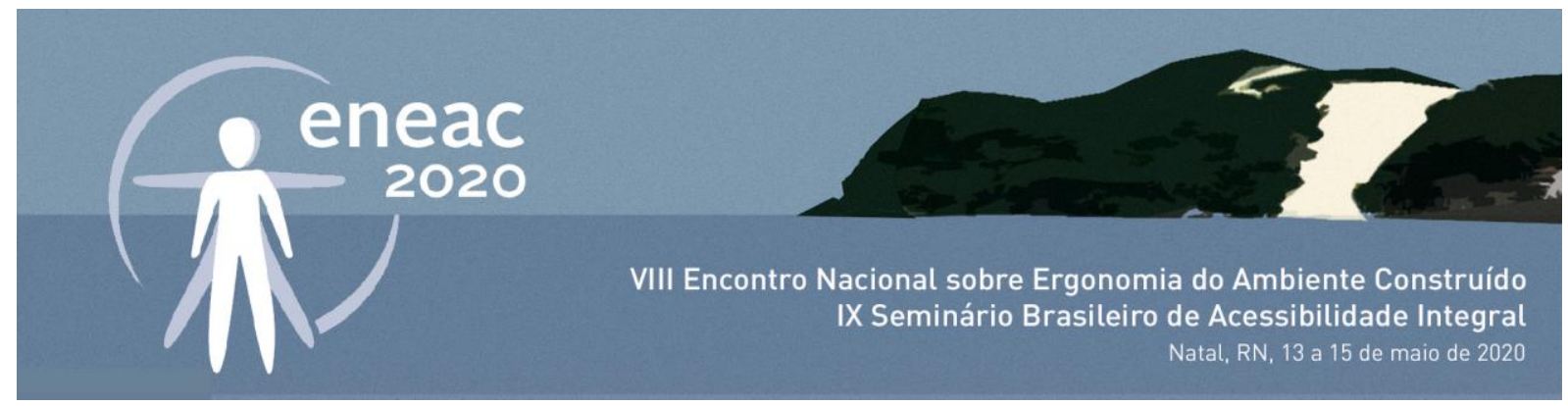

DUNCANSON, E.; VOLPE, J.; ACHILLES, C. A case study: natural outcomes of creating classroom space. National forum of educational administration and supervision journal, v. 26, n. 4, 2009.

EKAMBI-SCHMIDT, J. La percepción del habitat.pdf. Barcelona: G.Gili, 1974.

GOMES, N. R.; MEDEIROS, A. M. DE; TEIXEIRA, L. C. Autopercepção das condições de trabalho por professores de ensino fundamental. Revista CEFAC, v. 18, n. 1, p. 167-173, 2016.

GRANGAARD, E. M. Color and light effects on learning. Washington DC: [s.n.]. Disponível em: <http://files.eric.ed.gov/fulltext/ED382381.pdf>. Acesso em: 1 nov. 2017.

GREEN, D.; TURREL, P. School building investment and impact on pupil performance. Facilities Journal of Educational Administration, v. 23, n. 5/6, p. 253-261, 2005.

HIGGINS, S. et al. The Impact of School Environments: A literature review. Newcastle upon Tyne: [s.n.]. Disponível em: <http://citeseerx.ist.psu.edu/viewdoc/download;jsessionid=195B2B0D479CAAC7057E6BBE1EAA9DB8?doi=10.1.1.231.7213 \&rep=rep1\&type=pdf>. Acesso em: 1 nov. 2017.

IIDA, I. Ergonomia: projeto e produção. 2. ed. São Paulo: Edgard Blücher, 2005.

INEP. Explorando o aprendizado: dados da prova Brasil 2017. Disponível em: <https://www.qedu.org.br/cidade/3788recife/explorar?grade=9\&discipline=1\&dependence=2\&zoom=2\&sort=name\&sortDirection=asc\&visualization=isotope $>$. Acesso em: 4 abr. 2019.

LE PELLEY, M. E. et al. Attention and Associative Learning in Humans: An Integrative Review. Association, v. 142, n. 10, p. 1111-1140, 2016.

MAXWELL, L. E.; EVANS, G. W. The effects of noise on pre-school children's pre-reading skills. Journal of Environmental Psychology, v. 20, p. 91-97, 2000.

NICO, M. A.; LIUZZI, S.; STEFANIZZI, P. Evaluation of thermal comfort in university classrooms through objective approach and subjective preference analysis. Applied ergonomics, v. 48, p. 111-20, maio 2015.

PENTEADO, R. Z.; PEREIRA, I. M. T. B. Qualidade de vida e saúde vocal de professores. Revista de Saúde Pública, v. 41, n. 2 , p. 236-243, abr. 2007.

QUEIROZ, C. S. DE. Salas cheias. Disponível em: <https://www.revistaeducacao.com.br/salas-cheias/>. Acesso em: 10 nov. 2019.

RAMOS, M. N. Parecer CNE/CEB n 8/2010: Estabelece normas para aplicação do inciso IX do artigo $4^{\circ}$ da Lei $n^{\circ} 9.394 / 96$ (LDB), que trata dos padrões mínimos de qualidade de ensino para a Educação Básica pública. Brasil: [s.n.]. Disponível em: <https://www.nber.org/papers/w15827.pdf>.

RAPOPORT, A. The Meaning of the Built Environment: a nonverbal communication approach. Tucson: University of Arizona Press, 1982

RUEDA, F. Bateria Psicológica para Avaliação da Atenção (BPA). São Paulo: Vetor, 2013.

SIQUARA, G. M. A influência da memória operacional no desempenho acadêmico em crianças de $\mathbf{7}$ a $\mathbf{1 2}$ anos de idade. [s.I.] Universidade Federal da Bahia, 2014

STERNBERG, R. J.; COSTA, R. C.; HAASE, V. G. Psicologia cognitiva. [s.I.] Artmed, 2008.

TANNER, C. K. Explaining relationships among student outcomes and the school's physical environment. Journal of Advanced Academics, v. 19, n. 3, p. 444-471, 2008

TEDDLIE, C.; KIRBY, P. C.; STRINGFIELD, S. Effective versus Ineffective Schools: Observable Differences in the Classroom. American Journal of Education, v. 97, n. 3, p. 221-236, 1989.

ULINE, C. L. et al. Improving the Physical and Social Environment of School : A Question of EquityJournal of School Leadership, 2010.

VILLAROUCO, V. M. Modelo de avaliação de projetos: enfoque cognitivo e ergonômico. [s.I.] Universidade Federal de Santa Catarina, 2001. 


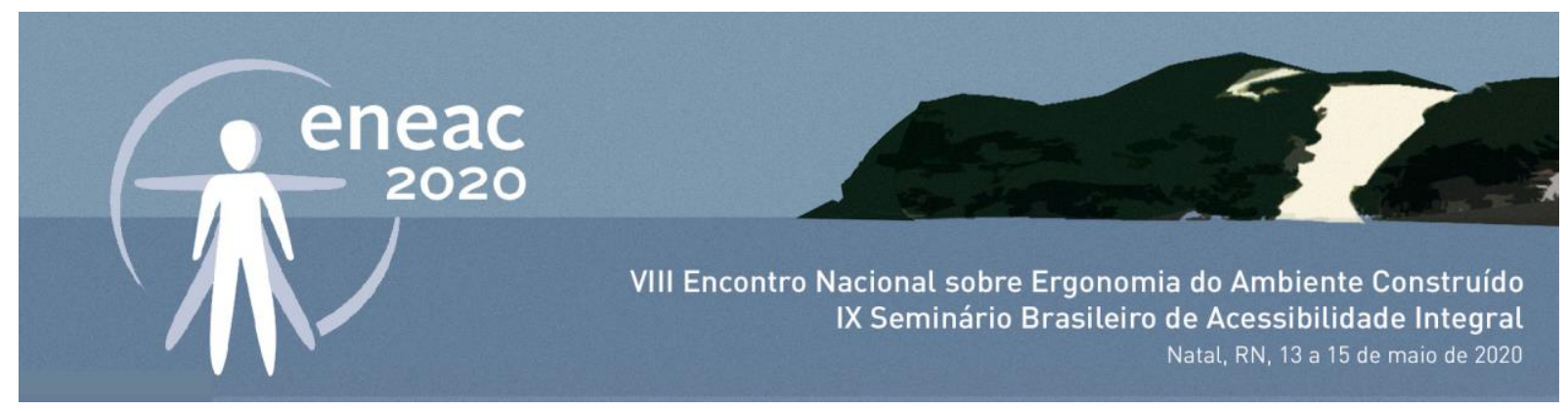

WARGOCKI, P.; WYON, D. P. The Effects of Moderately Raised Classroom Temperatures and Classroom Ventilation Rate on the Performance of Schoolwork by Children (RP-1257). HVAC\&R RESEARCH, v. 13, n. 2, 2007.

WOHLWILL, J. F.; VLIET, W. VAN. Habitats for Children: The Impacts of Density. Hillsdale: Lawrence Erlbaum associates, 1985.

WURTMAN, R. J. The Effects of Light on the Human Body. Scientific American, v. 233, n. 1, p. 68-77, jul. 1975. 